\title{
ENDOTHELIN-1 CONCENTRATIONS IN THE INTERNAL JUGULAR AND AZYGOUS VEINS IN MULTIPLE SCLEROSIS PATIENTS: THE RESULTS OF A PILOT STUDY
}

\author{
Marian Simka, Tomasz Ludyga, Piotr Janas, Marek Kazibudzki, Paweł Latacz \\ EUROMEDIC Specialist Clinics, Department of Vascular and Endovascular Surgery, Katowice, \\ Poland
}

\begin{abstract}
Objectives: In this pilot study we examined the potent vasoconstrictor, endothelin-1, in the blood of multiple sclerosis patients in the context of chronic cerebrospinal venous insufficiency hypothesis. For this purpose we measured endothelin-1 concentrations in blood samples that were obtained during selective catheterisation of the main veins draining the central nervous system: the internal jugular veins and the azygous vein.

Material and methods: We measured endothelin-1 concentrations in peripheral blood in nine multiple sclerosis patients and five healthy controls. In multiple sclerosis patients this peptide was also evaluated in blood samples obtained from the internal jugular veins and azygous vein. Also, in five patients peripheral endothelin-1 levels were measured one and seven days after angioplasty for stenosed internal jugular veins.

Results: We found similar concentrations of endothelin-1 in peripheral blood in multiple sclerosis patients and healthy controls, a higher endothelin-1 level in the upper part of right internal jugular veins, and unchanged concentrations of this peptide in peripheral blood following angioplasty.

Conclusions: Considering the pilot nature of our trial and the small number of the patients and controls assessed, our findings should be interpreted with caution, but they may represent a useful framework for further research in this field. However, our study shows that it is unlikely that endothelin-1 circulating in the blood is responsible for the symptoms of multiple sclerosis.
\end{abstract}

Key words: endothelin-1, multiple sclerosis, jugular vein, azygous vein.

\author{
ORIGINAL PAPER \\ Phlebological Review 2014; 22, 1: 18-23 \\ DOI: $10.5114 /$ pr.2014.46049
}

Submitted: 8.05.2014

Accepted: 16.06 .2014

\section{ADDRESS FOR CORRESPONDENCE:}

Marian Simka, EUROMEDIC Specialist Clinics, Department of Vascular and Endovascular Surgery, Katowice, Poland, e-mail: mariansimka@poczta.onet.pl

\section{INTRODUCTION}

The recent discovery of venous malformations obstructing venous outflow from the central nervous system in multiple sclerosis (MS) suggests that vascular mechanisms may be responsible for the initiation and progression of this disease [1]. Although MS is traditionally thought to be an autoimmune pathology, the venous hypothesis is not necessarily contrary to its currently ruling paradigm but - on the contrary - can represent the other side of the same coin: a very complex pathological entity including both immune and vascular disorders. In this pilot study we examined the potent vasoconstrictor, endothelin-1 (ET-1), in the blood of MS patients in the context of this venous hypothesis. For this purpose we measured ET-1 in blood samples that were obtained during selective catheterisation of the main veins draining the central nervous system: the internal jugular veins (IJVs) and the azygous vein. Taking into account the small number of assessed patients, the results of this preliminary study should be interpreted with caution. Nonetheless, our findings can be a useful framework for further research in this field.

\section{MATERIAL AND METHODS}

Concentrations of ET-1 in the blood samples were determined using Endothelin (1-21) enzyme immunoassay (Biomedica Medizinprodukte $\mathrm{GmbH} \& \mathrm{Co} \mathrm{KG}$, Vienna, Austria), and the absorbance was measured with ELISA microplate reader SIRIO-S (Radim SpA, Pomezia, Italy). In order to avoid the loss of bioactivity, after the blood samples were drawn they were immediately cooled to $4^{\circ} \mathrm{C}$, centrifuged, and then the serum was stored deeply frozen until the time of measurements.

There were assessed 9 patients ( 6 women and 3 men) with clinically defined MS, aged 32-61, with a median 
age of 48 years, and 5 healthy volunteer controls (all of them were women) aged 25-36 years, with a median age of 32 years. The majority of MS patients presented with the progressive form of the disease. Relapsing-remitting MS patients did not exhibit an active relapse at the time of assessment. The patients were not receiving immunomodulating drugs during the study.

Blood samples from the upper and lower parts of left and right IJVs, and from the proximal portion of the azygous vein were taken during venography of these veins. If the venography revealed a significant stenosis, balloon angioplasty of such lesions was performed. Blood samples of peripheral blood (from the cubital vein) were taken from MS patients and from healthy controls. Additionally, in $5 \mathrm{MS}$ patients (all of them women) samples of peripheral blood were taken 1 and 7 days after angioplasty (all these patients underwent angioplasty of malformed IJVs, while the azygous vein was found normal). Details of our venographic and angioplastic protocol can be found in our previous paper [2].

Although all MS patients were screened before venography for venous abnormalities using colour Doppler sonography, final diagnosis of vascular pathology was given according to the catheter venography findings. Healthy controls were also screened for the presence of venous pathology. Since venographic assessment in the controls was not possible (considering the risk of this invasive test we found it unethical to do it in a healthy volunteer), diagnosis of such a vascular abnormality was given using criteria of chronic cerebrospinal venous insufficiency (CCSVI) that were suggested by Zamboni et al. [1]. However, we used only four out of five original sonographic criteria (the flow in intracranial veins was not evaluated), since we had no access to a sonographic system equipped with multigate quality Doppler profiles, which would enable a proper assessment of intracranial veins [3].

This pilot study was a part of the open-label trial on the safety and efficacy of endovascular treatment for chronic cerebrospinal venous insufficiency [1] in MS patients. The entire study protocol, including imaging diagnostics of extracranial veins, catheter venography, and testing for ET-1 concentration was approved by the Bioethical Committee of the Regional Silesian Board of Physicians in Katowice, Poland (approval N $N^{\circ} 7 / 2010$, with amendment SIL/KB/103/555p/10). All patients and controls provided their consent to undergo the tests.

The $t$ test, adjusted for unequal variance (Welch test), was used to test the null hypothesis that the concentrations of ET-1 were equal, against the alternative hypothesis that these concentrations differed significantly between the patients and controls, between the veins assessed, and between pre- and postprocedural ET-1 values. The significance of the $p$ value was set at $<0.05$. Statistical analysis was performed using the PAST data analysis package (version 2.09; University of Oslo, Norway).

\section{RESULTS}

\section{Characteristics of venous pathology detected in MS patients during catheter venography}

Four patients presented with isolated stenosis of the left IJV (in one patient in combination with stenosis of the azygous vein), and the remaining five patients exhibited stenoses in both IJVs (in two cases outflow from both IJVs was equally compromised, in two cases left IJV was more affected, while in one case right IJV was more severely stenosed). Thus, in general, a pathological outflow from the left IJV appeared to be more compromised.

\section{Sonographic signs of CCSVI in healthy controls}

One control individual presented with severe stenosis and not detectable flow in one IJV (two positive sonographic criteria), and the other control person exhibited not detectable flow in one IJV (one positive criterion). Contralateral IJVs in these controls were unchanged. No sonographic abnormalities were found in both IJVs in the remaining three controls.

\section{Endothelin-1 concentrations in peripheral blood}

We found that mean ET-1 levels in peripheral blood, although slightly higher in the controls, did not differ significantly between MS patients and healthy individuals ( $p$ value of the Welch test was 0.34 ). Maximal and minimal values were also similar (Table 1).

\section{Endothelin-1 values in peripheral blood before and after angioplasty}

The patients exhibited nearly the same concentrations of ET-1 in peripheral blood before and after endovascular procedure ( $p$ values of the Welch test: before vs. 1 day, before vs. 7 days, and 1 day vs. 7 days were: $0.98,0.84$, and 0.87 , respectively). Details are given in Table 2 .

\section{Endothelin-1 concentrations in peripheral, jugular, and azygous venous blood}

This part of the study was performed in nine MS patients. Although an universal pattern could not be demonstrated, we found that ET-1 levels in the azygous vein, even in the case of stenosis of this vein, were slightly lower than in peripheral blood (statistical significance not reached, $p$ value of the Welch test: 0.61 ). On the contrary, ET-1 levels in the IJVs were higher than in peripheral blood, especially in the right IJV, i.e. in the vein exhibiting less compromised outflow. Nonetheless, statistical significances of these differences were not reached $(p>0.05)$. 
However, a statistical trend towards a higher ET-1 level in the upper part of the right IJV was demonstrated ( $p$ value of the Welch test for peripheral blood vs. upper right IJV: 0.15 , and for azygous vs. upper right IJV: 0.09). Details are given in Table 3.

\section{DISCUSSION}

Endothelin-1 is the member of endothelin peptide family. These peptides, in addition to their participation in many vascular pathologies, play important roles in physiological processes within the central nervous system and also in several neurological diseases: cerebral stroke, brain injury, subarachnoid haemorrhage, virus infection of the brain, and Alzheimer's disease. The endothelin family comprises three main isoforms: ET-1, ET-2, and ET-3. Endothelins act through their specific receptors: $\mathrm{ET}_{\mathrm{A}}$ and $\mathrm{ET}_{\mathrm{B}} . \mathrm{ET}_{\mathrm{B}}$ receptors are present in vascular endothelium and are responsible for vasodilatation through the release of nitric oxide and prostacyclin. Stimulation of $\mathrm{ET}_{\mathrm{A}}$ and $\mathrm{ET}_{\mathrm{B}}$ receptors that are found in vascular smooth muscles results in a strong, long-lasting, and almost irreversible vasoconstriction. Endothelin-1 may also directly constrict blood vessels through the generation of endothelium-derived thromboxane-A2. The net effect produced

Table 1. Endothelin-1 in peripheral blood in MS patients and healthy controls

\begin{tabular}{lcc}
\hline Parameter & MS patients & $\begin{array}{c}\text { Healthy } \\
\text { controls }\end{array}$ \\
\hline Number of the individuals tested & 9 & 5 \\
\hline Mean endothelin-1 & $\begin{array}{c}0.85 \pm 0.80 \\
\mathrm{fmol} / \mathrm{ml}\end{array}$ & $\begin{array}{c}1.27 \pm 0.71 \\
\mathrm{fmol} / \mathrm{ml}\end{array}$ \\
\hline concentration \pm SD & $2.94 \mathrm{fmol} / \mathrm{ml}$ & $2.24 \mathrm{fmol} / \mathrm{ml}$ \\
\hline Maximal value & $0.32 \mathrm{fmol} / \mathrm{ml}$ & $0.55 \mathrm{fmol} / \mathrm{ml}$ \\
\hline Minimal value &
\end{tabular}

by ET- 1 is determined by the balance between $\mathrm{ET}_{\mathrm{A}}$ and $\mathrm{ET}_{\mathrm{B}}$ receptors. Under physiological conditions such a net effect is usually vasoconstriction. In the brain both ET-1 and ET- 3 have been detected and it is known that these peptides are produced by endotheliocytes, neurons, and glial cells. It has also been demonstrated that in cerebral blood vessels ET-1 is released and acts from the abluminal (adventitial) and not from the endoluminal side. Endothelin-1 accounts for the majority of pathobiological effects exerted by endothelins, including the above-mentioned neurological pathologies [4-10]. In most of the tissues endothelins are primarily produced by endothelium, but in human brain the astrocytes are the main source of ET-1, especially in the settings of neuroischaemic disorders. Interestingly, ET-1 is released from astrocytes not only in the settings of ischaemia, but such a release can also be triggered by mechanical stimuli [11]. It is suspected that ET-1 protects these glial cells from ischaemia-driven injury [12] but an excess of ET-1 can worsen already compromised cerebral microcirculation. In addition to its vasoconstriction effects, ET-1 inhibits astroglial gap junctional permeability, triggers intracellular $\mathrm{Ca}^{2+}$ waves in astrocytes, and blocks further propagation of these waves. Thus, a normal communication between astrocytes can be switched off when the level of ET-1 in the brain is increased [13].

Some reports have already suggested a potential role for ET-1 in the pathophysiology of MS. Yet, these reports were rather inconsistent. Pache et al. evaluated ET-1 in $30 \mathrm{MS}$ patients and 30 healthy controls [14]. The authors found significantly higher ET-1 concentrations in MS patients in comparison with controls (2.0 vs. $1.5 \mathrm{pg} / \mathrm{ml})$. In this study all but two patients presented with non-active stage of the disease. Patients with active MS exhibited higher ET-1 concentrations (2.7 vs. $2.0 \mathrm{pg} / \mathrm{ml}$ ), while for clinical type of MS, EDSS score and relapse rate did not correlate with ET-1 plasma levels. In another study

Table 2. Endothelin-1 in peripheral blood before and after angioplasty

\begin{tabular}{lccc}
\hline Parameter & Before the procedure & 1 day after jugular angioplasty & $\begin{array}{c}\mathbf{7} \text { days after jugular } \\
\text { angioplasty }\end{array}$ \\
\hline Mean endothelin-1 concentration \pm SD & $0.99 \pm 1.10 \mathrm{fmol} / \mathrm{ml}$ & $1.01 \pm 1.24 \mathrm{fmol} / \mathrm{ml}$ & $1.14 \pm 1.15 \mathrm{fmol} / \mathrm{ml}$ \\
\hline Maximal value & $2.94 \mathrm{fmol} / \mathrm{ml}$ & $3.19 \mathrm{fmol} / \mathrm{ml}$ & $3.18 \mathrm{fmol} / \mathrm{ml}$ \\
\hline Minimal value & $0.32 \mathrm{fmol} / \mathrm{ml}$ & $0.25 \mathrm{fmol} / \mathrm{ml}$ & $0.43 \mathrm{fmol} / \mathrm{ml}$ \\
\hline
\end{tabular}

Table 3. Endothelin-1 concentrations in peripheral, jugular and azygous venous blood

\begin{tabular}{lcccccc}
\hline Parameter & Peripheral blood & $\begin{array}{c}\text { Right IJV: } \\
\text { upper part }\end{array}$ & $\begin{array}{c}\text { Right IJV: } \\
\text { lower part }\end{array}$ & $\begin{array}{c}\text { Left IJV: } \\
\text { upper part }\end{array}$ & $\begin{array}{c}\text { Left IJV: } \\
\text { lower part }\end{array}$ & Azygous vein \\
\hline $\begin{array}{l}\text { Mean endothelin-1 } \\
\text { concentration } \pm S D\end{array}$ & $0.85 \pm 0.80 \mathrm{fmol} / \mathrm{ml}$ & $1.87 \pm 1.83 \mathrm{fmol} / \mathrm{ml}$ & $0.99 \pm 1.11 \mathrm{fmol} / \mathrm{ml}$ & $0.94 \pm 0.86 \mathrm{fmol} / \mathrm{ml}$ & $0.92 \pm 1.17 \mathrm{fmol} / \mathrm{ml}$ & $0.68 \pm 0.61 \mathrm{fmol} / \mathrm{ml}$ \\
\hline Maximal value & $2.94 \mathrm{fmol} / \mathrm{ml}$ & $5.48 \mathrm{fmol} / \mathrm{ml}$ & $3.19 \mathrm{fmol} / \mathrm{ml}$ & $3.17 \mathrm{fmol} / \mathrm{ml}$ & $3.96 \mathrm{fmol} / \mathrm{ml}$ & $2.19 \mathrm{fmol} / \mathrm{ml}$ \\
\hline Minimal value & $0.32 \mathrm{fmol} / \mathrm{ml}$ & $0.28 \mathrm{fmol} / \mathrm{ml}$ & $0.13 \mathrm{fmol} / \mathrm{ml}$ & $0.35 \mathrm{fmol} / \mathrm{ml}$ & $0.17 \mathrm{fmol} / \mathrm{ml}$ & $0.12 \mathrm{fmol} / \mathrm{ml}$ \\
\hline
\end{tabular}


by this team on a group $20 \mathrm{MS}$ patients even higher ET-1 levels in the peripheral venous blood (mean: $3.5 \mathrm{pg} / \mathrm{ml}$ ) were found [15]. The authors hypothesised that the difference between the studies resulted from an action of immunomodulatory drugs, which were administered to the majority of MS patients in the study with lower ET-1 concentrations. In contrast to these two papers, a recent study by Jankowska-Lech et al. has shown significantly decreased ET-1 levels in MS patients when compared to the age-matched controls [16].

Considering the pilot nature of our trial and the small number of patients and controls assessed, our findings should be interpreted with great caution. It should be emphasised that in our pilot study the patients and controls were not matched for sex and age. In a study on healthy individuals the authors found higher ET-1 levels in older subjects [17]. Therefore, even if we did not confirm the results of the previous studies and found a similar concentration of ET-1 in peripheral blood in MS patients and healthy controls, perhaps a better designed study, with perfectly matched controls, would show a different result. Nonetheless, it should be remembered that a comparison between MS patients and the controls was not the main goal of our survey. Of note, we found a higher ET-1 level in the upper part of the right IJV in MS patients (although the statistical significance of this finding was not demonstrated) and an unchanged ET-1 concentrations in the peripheral blood after angioplasty of stenosed IJVs.

It is known that ET-1 is released from the brain, and a higher release of this peptide can be expected in the case of neurological pathology. However, ET-1 levels in peripheral blood are not only dependent on its cerebral production, but also on the release of this peptide from other organs and - importantly - on ET-1 cleavage in pulmonary circulation (through binding to pulmonary $\mathrm{ET}_{\mathrm{B}}$ receptors). Although ET-1 is stable in blood, it is removed in the lungs, over $50 \%$ in a single passage $[6,18]$. Probably in a case of efficient pulmonary cleavage, the peripheral concentration of ET-1 is not significantly increased, even if its cerebral release is abnormally high. Therefore, the phenomenon of pulmonary binding of ET-1 should be taken into account while interpreting the studies on this peptide. In addition, it has been found that peripheral ET-1 levels exhibit circannual fluctuations [19] which makes the problem even more complex.

Our finding of unchanged ET- 1 concentration following angioplasty of stenosed IJVs - respecting the preliminary nature of these results and small number of evaluated MS patients - sheds some light on a potential mechanism of clinical improvement after endovascular treatments for venous malformations in MS patients. It is known that ET- 1 is involved in the regulation of urinary bladder, and an increased blood ET-1 concentration can result in urinary bladder hyperactivity [19-21]. Intraventricular injection of ET-1 in animal experiments resulted in neurologi- cal symptoms comprising nystagmus, ocular clonus, tonic hindlimb extension, and generalised motor disturbances, the so-called barrel-rolling [22-24]. Since clinical improvements following venous angioplasty in MS patients are primarily seen in several domains, including bladder control, balance disturbances, nystagmus, and ataxia, it is tempting to speculate that they result from a decreased ET-1 level after the procedure. However, our results give no support for such a hypothetical mechanism. Endothelin-1 levels were not increased in peripheral blood before the treatment and were largely unchanged following the procedure. Thus, even taking into account that only five MS patients were examined, it is rather unlikely that ET-1 circulating in the blood is responsible for the above-mentioned MS symptoms. Still, a contribution of ET- 1 to these symptoms at the level of cerebral parenchyma or cerebral microcirculation cannot be ruled out.

Increased ET-1 levels in blood samples obtained from IJVs, primarily from the upper part of the right IJV, provides some additional information. Firstly, it confirms previous reports on increased production of ET- 1 by the brains of MS patients (it seems that in our study an excess in ET-1 was efficiently cleaved by the lungs, therefore the peripheral ET-1 level was unchanged). The upper part of the IJV carries almost exclusively blood drained from the brain, while the lower part of the IJV contains also blood coming from the facial vein that drains the skin, bones, and soft tissues of the head.

Secondly, our findings confirm the fact that in the settings of asymmetric stenosis of the IJVs blood flows preferentially toward the less affected jugular vein. However, it also means that any blood-dissolved substance coming from the diseased brain will preferentially flow through a healthy and not towards an already compromised vein. It should be remembered that the main cerebral venous pathways are interconnected at the confluence of sinuses, and venous blood in a healthy person can easily flow towards any internal jugular vein. Some authors suggested that CCSVI may develop due to an action of proinflammatory brain-released substances $[25,26]$. Nevertheless, our results suggest that such a mechanism is not very likely. Even if such a hypothetical substance exhibited a potential for triggering an extracranial venous lesion, it would be directed towards healthy IJV and then diluted in general circulation. On the other hand, many healthy individuals exhibit an asymmetric drainage pattern at the level of confluence of sinuses, with the majority of the blood being drained by only one IJV [27, 28]. Thus, these anatomical variants should also be taken into account while interpreting the results of our study.

Our pilot study can be an inspiration for further investigations on this topic. We suggest that the next studies on ET-1 in MS patients should focus on the concentration of this peptide drained from different parts of the brain (selective catheterisation of intracranial veins woud be needed), especially in the context of the locali- 
sation and activity of MS plaques. We are optimistic that such studies would explain some uncertainties related to a potential vascular contribution to MS pathology. However, given the invasive nature of such research, it seems unlikely that the proposed studies will be conducted very soon. Endovascular treatments for chronic cerebrospinal venous insufficiency are not a routine management. At the moment, blinded controlled randomised trials on such treatments are not yet completed, and therefore we wait for the results of these studies [29, 30].

\section{CONCLUSIONS}

Our study shows that it is rather unlikely that endothelin-1 circulating in the blood is responsible for the symptoms of multiple sclerosis. Considering the pilot nature of our trial and the small number of the patients and controls assessed, our findings should be interpreted with caution, but it may represent a useful framework for further research in this field.

\section{ACKNOWLEDGEMENTS}

The authors wish to thank the personnel of Anchem biochemical laboratory, Katowice, Poland for their technical support in conducting this study.

\section{References}

1. Zamboni P., Galeotti R., Menegatti E., Malagoni A.M., Tacconi G., Dall'Ara S., Bartolomei I., Salvi F. Chronic cerebrospinal venous insufficiency in patients with multiple sclerosis. J Neurol Neurosurg Psychiatry 2009; 80: 392-399.

2. Ludyga T., Kazibudzki M., Simka M., Hartel M., Swierad M., Piegza J., Latacz P., Sedlak L., Tochowicz M. Endovascular treatment for chronic cerebrospinal venous insufficiency: is the procedure safe? Phlebology 2010; 25: 286-295.

3. Zamboni P., Morovic S., Menegatti E., Viselner G., Nicolaides A.N. Screening for chronic cerebrospinal venous insufficiency (CCSVI) using ultrasound. Recommendations for a protocol. Int Angiol 2011; 6: 571-597.

4. Bohm F., Pernow J. The importance of endothelin-1 for vascular dysfunction in cardiovascular disease. Cardiovasc Res 2007; 76 : 8-18.

5. Dashwood M.R., Loesch A. Endothelin-1 as a neuropeptide: neurotransmitter or neurovascular effects? J Cell Commun Signal 2010; 4: 51-62.

6. DeNucci G., Thomas R., D’orleans-Juste P., Antunes E., Walder C., Warner T.D., Vane J.R. Pressor effects of circulating endothelin are limited by its removalin the pulmonary circulation and by the release of prostacyclin and endothelium-derived relaxing factor. Proc Natl Acad Sci U S A 1988; 85: 9797-9800.

7. Dehouck M.P., Vigne P., Torpier G., Breittmayer J., Cecchelli R., Frelin C. Endothelin-1 as a mediator of endothelial cell-pericyte interactions in bovine brain capillaries. J Cereb Blood Flow Metab 1997; 17: 464-469.

8. Krsmanović L.Z., Stojilković S.S., Balla T., al-Damluji S., Weiner R.I., Catt K.J. Receptors and neurosecretory actions of endothe- lin in hypothalamic neurons. Proc Natl Acad Sci U S A 1991; 88: 1124-1128.

9. Lee M.E., de la Monte S.M., Ng S.C., Bloch K.D., Quertermous T. Expression of the potent vasoconstrictor endothelin in the human central nervous system. J Clin Invest 1990; 86: 141-147.

10. Naidoo V., Naidoo S., Raidoo D.M. Immunolocalisation of endothelin-1 in human brain. J Chem Neuroanat 2004; 27: 193-200.

11. Ostrow L.W., Sachs F. Mechanosensation and endothelin in astrocytes - hypothetical roles in CNS pathophysiology. Brain Res Rev 2005; 48: 488-509.

12. Ho M.C., Lo A.C., Kurihara H., Yu A.C., Chung S.S., Chung S.K. Endothelin-1 protects astrocytes from hypoxic/ischemic injury. FASEB J 2001; 15: 618-626.

13. Blomstrand F., Giaume C., Hansson E., Ronnback L. Distinct pharmacological properties of ET-1 and ET-3 on astroglial gap junctions and Ca2+ signaling. Am J Physiol 1999; 277 : C616-617.

14. Pache M., Kaiser H.J., Akhalbedashvili N., Lienert C., Dubler B., Kappos L., Flammer J. Extraocular blood flow and endothelin-1 plasma levels in patients with multiple sclerosis. Eur Neurol 2003; 49: 164-168.

15. Haufschild T., Shaw S.G., Kesselring J., Flammer J. Increased endothelin-1 plasma levels in patients with multiple sclerosis. J Neuroophthalmol 2001; 21: 37-38.

16. Jankowska-Lech I., Bik Z., Wolinska E., Terelak-Borys B., Grabska-Liberek I., Palasik W. Endothelin-1 (ET-1) plasma levels in multiple sclerosis (MS) patients. Acta Ophthalmologica 2011; 89 (Suppl): 246.

17. Komatsumoto S., Nara M. Changes in the level of endothelin-1 with aging. Nihon Ronen Igakkai Zasshi 1995; 32: 664-669.

18. Langleben D., Dupuis J., Langleben I., Hirsch A.M., Baron M., Senécal J.L., Giovinazzo M. Etiology-specific endothelin-1 clearance in human precapillary pulmonary hypertension. Chest 2006; 129: 689-695.

19. Kruse H.J., Wieczorek I., Hecker H., Creutzig A., Schellong S.M. Seasonal variation of endothelin-1, angiotensin II, and plasma catecholamines and their relation to outside temperature. J Lab Clin Med 2002; 140: 236-241.

20. Ogawa T., Sasatomi K., Hiragata S., Seki S., Nishizawa O., Chermansky C.J., Pflug B.R., Nelson J.B., Chancellor M.B., Yoshimura N. Therapeutic effects of endothelin-A receptor antagonist on bladder overactivity in rats with chronic spinal cord injury. Urology 2008; 71: 341-345.

21. Westfall T.D., McCafferty G.P., Pullen M., Ventre J., Eybye M., Jugus M.J., Brooks S.A., Hieble J.P., Brooks D.P. Effect of endothelin on bladder contraction: potential role in bladder hyperactivity. Pharmacology 2003; 69: 7-11.

22. Chew B.H., Weaver D.F., Gross P.M. Dose-related potent brain stimulation by the neuropeptide endothelin-1 after intraventricular administration in conscious rats. Pharmacol Biochem Behav 1995; 51: 37-47.

23. Gross P.M., Beninger R.J., Shaver S.W., Wainman D.S., Espinosa F.J., Weaver D.F. Metabolic and neuroanatomical correlates of barrel-rolling and oculoclonic convulsions induced by intraventricular endothelin-1: a novel peptidergic signaling mechanism in visuovestibular and oculomotor regulation? Exp Brain Res 1993; 95: 397-408.

24. Souza-Rodrigues R.D., Costa A.M., Lima R.R., Dos Santos C.D., Picanco-Diniz C.W., Gomes-Leal W. Inflammatory resonse and white matter damage after microinjections of endothelin-1 into the rat striatum. Brain Res 2008; 1200: 78-88. 
25. Baracchini C., Perini P., Calabrese M., Causin F., Rinaldi F., Gallo $\mathrm{P}$. No evidence of chronic cerebrospinal venous insufficiency at multiple sclerosis onset. Ann Neurol 2011; 69: 90-99.

26. Yamout B., Herlopian A., Issa Z., Habib R.H., Fawaz A., Salame J., Wadih A., Awdeh H., Muallem N., Raad R., Al-Kutoubi A. Extracranial venous stenosis is an unlikely cause of multiple sclerosis. Mult Scler 2010; 16: 1341-1348.

27. Beards S.C., Yule S., Kassner A., Jackson A. Anatomical variation of cerebral venous drainage: the theoretical effect on jugular bulb blood samples. Anaesthesia 1998; 53: 627-633.

28. Metz C., Holzschuh M., Bein T., Woertgen C., Rothoerl R., Kallenbach B., Taeger K., Brawanski A. Monitoring of cerebral oxygen metabolism in the jugular bulb: reliability of unilateral measurements in severe head injury. J Cereb Blood Flow Metab 1998; 18: 332-343.

29. Siskin G.P., Haskal Z.J., McLennan G., Dake M.D., Haacke E.M., McDonald S., Royal W. 3rd, Vedantham S., Hubbard D., Sclafani S.J., Andrews R.T., Sauder H. Development of a research agenda for evaluation of interventional therapies for chronic cerebrospinal venous insufficiency: proceedings from a Multidisciplinary Research Consensus Panel. J Vasc Interv Radiol 2011; 22: 587-593.

30. Zamboni P., Menegatti E., Galeotti R., Malagoni A.M., Tacconi G., Dall'Ara S., Bartolomei I., Salvi F. The value of cerebral Doppler venous haemodynamics in the assessment of multiple sclerosis. J Neurol Sci 2009; 282: 21-27. 